\title{
Remote Temperature Sensor Based on Tamm Resonance
}

\author{
Zaky A. Zaky ${ }^{1}$ (D) Ashour M. Ahmed ${ }^{1} \cdot$ Arafa H. Aly ${ }^{1}$ (D)
}

Received: 25 January 2021 / Accepted: 9 March 2021 / Published online: 22 March 2021

(C) Springer Nature B.V. 2021

\begin{abstract}
A highly-sensitive remote temperature sensor based on Tamm resonance is proposed using a one-dimensional photonic crystal. The proposed structure is prism $/ \mathrm{Ag} / \mathrm{Toluene} / \mathrm{SiO}_{2} /\left(\mathrm{PSi}_{1} / \mathrm{PSi}_{2}\right)^{\mathrm{N}} / \mathrm{Si}$. The transfer matrix method is used to discuss the interaction between the structure and the S-polarization of the incident radiation waves. We optimized the structure by studying the effect of the incident angle, the thickness of the first and second layers of the photonic crystal unit cell, the porosity of them, and the thickness of the toluene layer. High sensitivity, high signal-to-noise ratio, and very low resolution are achieved due to the coupling between the porous silicon photonic crystal properties and Tamm resonance that makes it very distinguished compared to previous works.
\end{abstract}

Keywords Photonic crystal $\cdot$ Remote temperature sensor $\cdot$ Tamm resonance $\cdot$ Sensitivity

\section{Introduction}

Temperature sensing is probably the most important parameter in all branches of science. In daily life, temperature sensors are widely used in aerodynamics, metrology, climate and marine research, medicine, chemistry, biology, military technology, air conditioning, all heating and cooling devices, the storage of food, and others [1].

Optical thermometry has attracted great attention for remote temperature sensing. One method of optical thermometry is called luminescence temperature sensing (LTS) using a $\mathrm{Gd}_{2} \mathrm{O}_{3}$ host doped with rare-earth ions [2]. Even though $\mathrm{Gd}_{2} \mathrm{O}_{3}$ has a wide energy bandgap $(5.6 \mathrm{eV})$, high refractive index (1.50-2.05), low phonon energy $\left(600 \mathrm{~cm}^{-1}\right)$, excellent thermal and chemical stability, high mechanical strength, and high melting point, and $\mathrm{Gd}_{2} \mathrm{O}_{3}$ host doped with rare-earth ions was prepared by a simple and cost-effective process, the signal to noise ratio of these sensors need to be enhanced $[1,2]$.

Zaky A. Zaky

zaky.a.zaky@science.bsu.edu.eg

Arafa H. Aly

arafaaly@aucegypt.edu

Ashour M. Ahmed

ashour.mohamed@science.bsu.edu.eg

1 TH-PPM Group, Physics Department, Faculty of Sciences, Beni-Suef University, Bani Sweif, Egypt
Infectious substances testing is not nationally available in some countries so the specimens should be transported or stored. The correct handling of infectious substances during storage transportation is very important. Specimens that can be delivered to the laboratory promptly should be stored at $2-$ $8^{\circ} \mathrm{C}$. If further delays are expected, Specimens shall be frozen to extremely low temperatures (from $-20^{\circ} \mathrm{C}$ to $-70{ }^{\circ} \mathrm{C}$ ) [3]. So, the presence of a remote sensor with high performance and covers this wide range of temperatures may help in the correct handling of infectious substances.

Since 1987, Yablonovitch [4] proposed an artificial periodic array with a new property that is called a photonic bandgap. He presented the first explanation about the photonic crystal. Then, this field attracted visual attention in different applications such as chemical sensors [5, 6], biosensors [7-9], filters [10, 11], optical lenses [12], solar cells [13], and other applications [14-21]. Recently, the main challenge is how to use Nanomaterials with a very small size to create smart structures that can be used as complex and sophisticated devices [22-24].

Photonic crystals are periodic refractive index structure arrays as a function of one-dimension, two-dimension, or all three-dimension space. At the interfaces between every two different layers, a portion of the incident wave is reflected. Due to the destructive interference between the incident waves and reflected waves, a standing wave is formed. So, a certain wavelength range is prevented from propagating through the photonic crystal [4]. Recently, photonic crystal sensors have attracted considerable support from researchers and organizations to overcome 
technological challenges. Researchers seek to minimize the size of the circuit to use it as integrated chip sensors. Moreover, they try to enhance the performance of sensors to be able to accurately measure and detect different biological and physical parameters [15].

Srivastava et al. [25] suggested a structure based on surface plasmon waveguide with a sensitivity of $70 \mathrm{pm} /{ }^{\circ} \mathrm{C}$. Geng et al. [26] proposed a compact temperature fiber sensor based on photonic crystal and they obtained a sensitivity of $61 \mathrm{pm} /{ }^{\circ} \mathrm{C}$. Chen et al. [27] designed a sensor based on a plasmonic resonant absorber and achieved a sensitivity of $0.27 \mathrm{~nm} /{ }^{\circ} \mathrm{C}$. Then, Rajasekar et al. [28] proposed a hexagonal photonic crystal ring resonator as a pressure and temperature sensor and recorded a sensitivity of $66.6 \mathrm{pm} /{ }^{\circ} \mathrm{C}$. Kumar et al. [29] presented experimental temperature sensors using the Tamm plasmon resonance with a sensitivity of $7.8 \times 10^{-4} /{ }^{\circ} \mathrm{C}$.

One-dimensional photonic crystals (1D-PC) have generated attention because they are more affordable and easy to manufacture compared with the other two types [30]. A high refractive index contrast between used layers or their thicknesses is used to increase the PBG range. Also, we can use the Tamm plasmon resonance to increase the PBG range. Tamm plasmon is the appearance of resonant dip inside the PBG by adding a metallic layer in front of the one-dimensional photonic crystal [31]. On the contrary of surface plasmon resonance, Tamm plasmon can occur in both $\mathrm{S}$ and $\mathrm{P}$ polarization and at any incidence angle [32]. The resonant dip plays an important role in many applications of photonic crystals such as waveguides, high Q cavities, and optical filters $[6,33]$. The dip position is shifted to a higher or lower wavelength with any change in the effective refractive index $\left(\mathrm{n}_{\text {eff }}\right)$ of the structure or the surrounding medium. In this case, the PBG appears as if it were a complete bandgap and gives the chance for the resonant dip to be shifted over a wide bandgap. Recently, porous silicon (PSi) is a very hot two-dimensional material to be used in photonic crystals [34-38]. It has a low mass and high surface area within a small volume. The optical properties of PSi can be controlled by varying the size of pores or their density and the type of filling material [35].

The novelty and creativity in this work are due to many reasons. Firstly, the proposed structure is simple and recorded high performance for remote temperature sensing due to the coupling between the porous silicon 1D-PC and Tamm plasmon resonance. Also, for the first time and in contrast to the ordinary $[39,40]$ according to the best of our knowledge, the increase of the incident angle has a negative effect on the sensitivity when the resonant dip approaches the edge of the PBG (Fig. 5). Finally, This sensor may help in the correct handling of infectious substances.

\section{Sensor Design}

In Fig. 1, the proposed structure is a binary onedimensional photonic crystal composed of two porous silicon layers ( $\mathrm{PSi}_{1} / \mathrm{PSi}_{2}$ ) with different porosity according to many previous experimental works [41-43]. The porosity of the first silicon layer is $P_{1}$ with thickness $d_{1}$, and the second one is $P_{2}$ with a thickness $d_{2}$. To achieve Tamm resonance, we deposited a metallic layer on a prism of glass $\left(\mathrm{n}_{0}=1.5\right)$ in front of the structure [44-46]. Due to the small absorption loss of Ag (imaginary part of the dielectric constant) compare with other metals, we used it with a thickness $d_{m}$ [34].

Between the metallic layer and $\left(\mathrm{PSi}_{1} / \mathrm{PSi}_{2}\right)^{\mathrm{N}} / \mathrm{Si}$, we introduce toluene liquid as a very sensitive layer to temperature with thickness $d_{T}$ [47]. To prevent toluene from entering the pores of silicon, we separate them by silicon dioxide layer with thickness $d_{c}$ that can be done experimentally [48]. Different practical photonic crystals with hollow cores infiltrated with toluene had been published [47, 49-52].

To control the thickness of the toluene layer during the fabrication process, a certain material can be deposited during the fabrication, as clear in step 1 in Fig. 1(A). The structure is packaged using a good thermal conductive material, as clear in step 2. A small hall will be drilled in the center of the layer that will be filled with toluene, as clear in step 3 . The material in this layer will be removed with a strong acid (etching), as clear in steps $4-5$. The empty layer will be filled with toluene, as clear in step 6 . The drilled hall will be closed, as clear in step 7. Therefore, the suggested biosensor consists of prism/Ag/T/C/(PSi $\left.1 / \mathrm{PSi}_{2}\right)^{\mathrm{N}} / \mathrm{Si}$.

\section{Theoretical Model}

The transfer matrix method (TMM) is used to discuss the interaction between the proposed structure and the incident radiation waves. As the evanescent fields produced with spolarization are stronger than p-polarization [53], we used spolarization in our simulations.

TMM details were mentioned in lists of articles [54, 55]. By using the following matrices the suggested structure will be characterized:

$J=\left(\begin{array}{ll}J_{11} & J_{12} \\ J_{21} & J_{22}\end{array}\right)=\left(j_{m}\right)\left(j_{T}\right)\left(j_{c}\right)\left(j_{1} j_{2}\right)^{N}$,

where $\mathrm{J}_{11}, \mathrm{~J}_{12}, \mathrm{~J}_{21}$ and $\mathrm{J}_{22}$ are the elements of the transfer matrix for the structure. $\mathrm{j}_{\mathrm{m}}, \mathrm{j}_{\mathrm{T}}, \mathrm{j}_{\mathrm{c}}, \mathrm{j}_{1}$, and $\mathrm{j}_{2}$ are the characteristic matrix for the metallic layer, toluene layer, $\mathrm{SiO}_{2}$ layer, $\mathrm{PSi}_{1}$, and $\mathrm{PSi}_{2}$ : 
Fig. 1 (A) Steps of toluene layer fabrication (B) Schematic diagram of the suggested temperature sensor
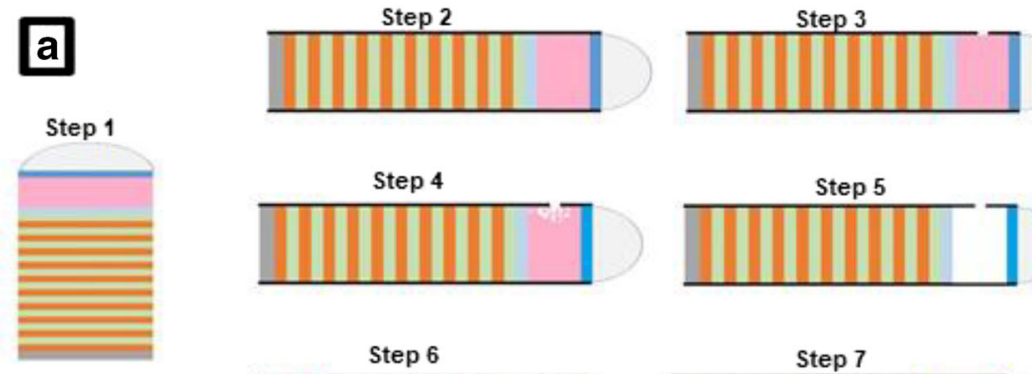

Step 6
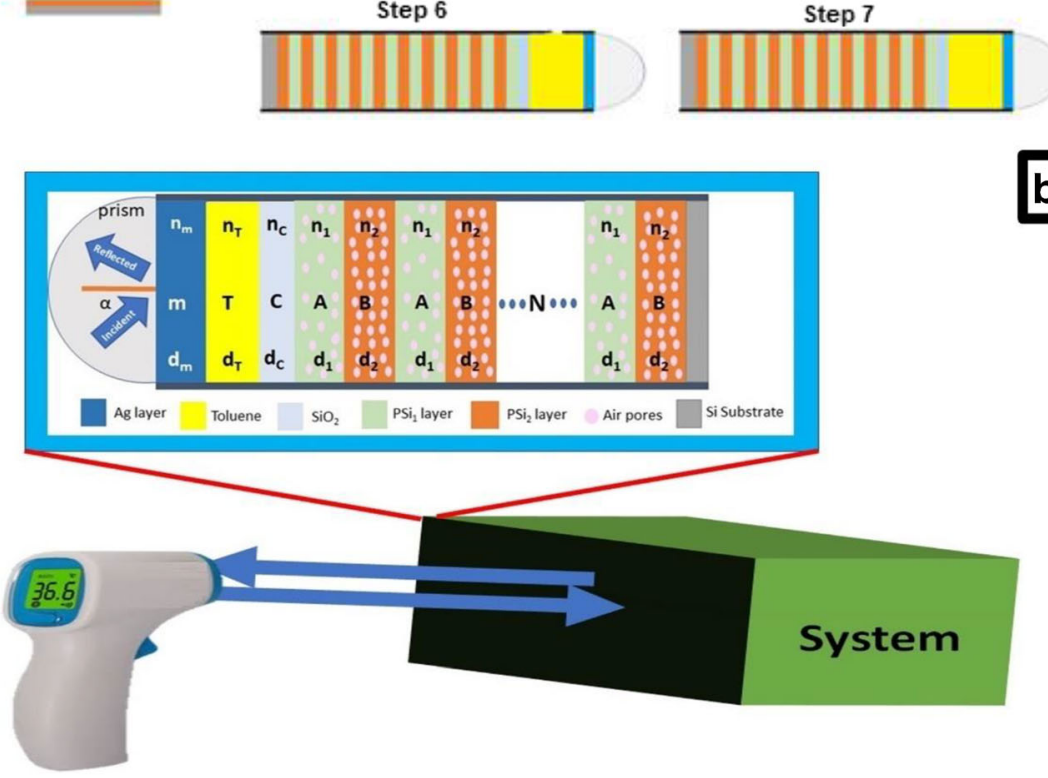

$$
\begin{aligned}
\mathrm{j}_{\mathrm{m}} & =\left(\begin{array}{ll}
\cos \beta_{\mathrm{m}} & -\frac{\mathrm{i} \sin \beta_{\mathrm{m}}}{\mathrm{p}_{\mathrm{m}}} \\
-\mathrm{i} \mathrm{p}_{\mathrm{m}} \sin \beta_{\mathrm{m}} & \cos \beta_{\mathrm{m}}
\end{array}\right), \\
\mathrm{j}_{\mathrm{T}} & =\left(\begin{array}{ll}
\cos \beta_{\mathrm{T}} & -\frac{\mathrm{i} \sin \beta_{\mathrm{T}}}{\mathrm{p}_{\mathrm{T}}} \\
-\mathrm{i} \mathrm{p}_{\mathrm{T}} \sin \beta_{\mathrm{T}} & \cos \beta_{\mathrm{T}}
\end{array}\right), \\
\mathrm{j}_{\mathrm{c}} & =\left(\begin{array}{ll}
\cos \beta_{\mathrm{c}} & -\frac{\mathrm{i} \sin \beta_{\mathrm{c}}}{\mathrm{p}_{\mathrm{c}}} \\
-\mathrm{i} \mathrm{p}_{\mathrm{c}} \sin \beta_{\mathrm{c}} & \cos \beta_{\mathrm{c}}
\end{array}\right), \\
\mathrm{j}_{1} & =\left(\begin{array}{ll}
\cos \beta_{1} & -\frac{\mathrm{i} \sin \beta_{1}}{\mathrm{p}_{1}} \\
-\mathrm{i} \mathrm{p}_{1} \sin \beta_{1} & \cos \beta_{1}
\end{array}\right), \\
\mathrm{j}_{2} & =\left(\begin{array}{ll}
\cos \beta_{2} & -\frac{\mathrm{i} \sin \beta_{2}}{\mathrm{p}_{2}} \\
-\mathrm{i} \mathrm{p}_{2} \sin \beta_{2} & \cos \beta_{2}
\end{array}\right)
\end{aligned}
$$

where the phase differences $(\beta)$ is given by;

$\beta_{\mathrm{i}}=\frac{2 \pi \mathrm{n}_{\mathrm{i}} \mathrm{d}_{\mathrm{i}} \cos \alpha_{\mathrm{i}}}{\lambda}, \mathrm{i}=\mathrm{m}, \mathrm{T}, \mathrm{c}, 1$, and 2

Also, $\mathrm{p}$ for the s-polarized (TE) wave is given by $\mathrm{p}_{\mathrm{i}}=\mathrm{n}_{\mathrm{i}} \cos \alpha_{\mathrm{i}}$. The angles of incidence $\alpha_{\mathrm{m}}, \alpha_{\mathrm{T}}, \alpha_{\mathrm{c}}, \alpha_{1}$, and $\alpha_{2}$ on the $\mathrm{Ag}$, toluene, $\mathrm{SiO}_{2}, \mathrm{Psi}_{1}$, and $\mathrm{Psi}_{2}$ layers satisfy Snell's law: $\mathrm{n}_{0} \sin \alpha_{0}=\mathrm{n}_{\mathrm{m}} \sin \alpha_{\mathrm{m}}=\mathrm{n}_{\mathrm{T}} \sin \alpha_{\mathrm{T}}=\mathrm{n}_{\mathrm{c}} \sin \alpha_{\mathrm{c}}=\mathrm{n}_{1} \sin \alpha_{1}$

$$
=\mathrm{n}_{2} \sin \alpha_{2},
$$

$\left(j_{1} j_{2}\right)$ will be repeated for $N$ periods based on the Chebyshev polynomials of the second kind. The coefficient of reflection is computed according to the following equation:

$$
r=\frac{\left(J_{11}+J_{12} p_{s}\right) p_{0}-\left(J_{21}+J_{22} p_{s}\right)}{\left(J_{11}+J_{12} p_{s}\right) p_{0}+\left(J_{21}+J_{22} p_{s}\right)},
$$

where $\mathrm{p}_{0}=\mathrm{n}_{0} \cos \alpha_{0}$ (for prism) and $\mathrm{p}_{\mathrm{s}}=\mathrm{n}_{\mathrm{s}} \cos \alpha_{\mathrm{s}}$ (for substrate). Besides, $\alpha_{0}$ is referring to the incident angle of the radiation waves on the $\mathrm{Ag} / \mathrm{T} / \mathrm{C} /\left(\mathrm{PSi}_{1} / \mathrm{PSi}_{2}\right)^{\mathrm{N}} / \mathrm{Si}$ structure. Finally, the reflectance of the suggested design is [56]:

$$
\mathrm{R}=100 *\left|\mathrm{r}^{2}\right|
$$

\section{Results and Discussions}

Firstly, the refractive index of the metallic layer $\left(\mathrm{n}_{\mathrm{m}}\right)$, the toluene layer $\left(\mathrm{n}_{\mathrm{T}}\right), \mathrm{SiO}_{2}$ layer $\left(\mathrm{n}_{\mathrm{C}}\right), \mathrm{PSi}_{1}\left(\mathrm{n}_{1}\right)$, and $\mathrm{PSi}_{2}\left(\mathrm{n}_{2}\right)$ will be calculated as a function of wavelength (infra-red 
range) and temperature (from $-80^{\circ} \mathrm{C}$ to $80^{\circ} \mathrm{C}$ ) both. Then, we will study the effect of the angle of the incident radiation, the thickness of the first and second layers of the photonic crystal unit cell $\left(\mathrm{d}_{1}\right.$ and $\left.\mathrm{d}_{2}\right)$, the porosity of them $\left(\mathrm{P}_{1}\right.$ and $\left.\mathrm{P}_{2}\right)$, and the effect of the toluene layer thickness on the designed sensor performance. Finally, the analysis of the sensor will be discussed.

\subsection{Refractive Index of $\mathbf{A g}$}

The increase in temperature causes an increase in the collision frequency of electrons $\left(\omega_{\mathrm{c}}\right)$. Consequently, the metal absorption increases with the temperature increase. On the other hand, plasma frequency $\omega_{\mathrm{p}}$ will be considered as a constant value over the temperature range [57]. The refractive index of Ag-metal is calculated by using the Drude model [58]:

$\mathrm{n}_{\mathrm{m}}=\sqrt{1-\frac{\omega_{\mathrm{p}}^{2}}{\omega\left(\omega-\mathrm{i} \omega_{\mathrm{c}}\right)}}$,

where $\omega_{\mathrm{p}}=8.28 \mathrm{eV}, \omega_{\mathrm{c}}(\mathrm{T})=\left(\frac{\omega_{\mathrm{c}}(\mathrm{T}=300)}{300^{\frac{1}{3}}}\right) \mathrm{T}^{1 / 3}$, and $\omega_{\mathrm{c}}(\mathrm{T}=$ $300)=0.048 \mathrm{eV}[58,59]$.

\subsection{Refractive Index of Toluene}

The refractive index of toluene $\left(\mathrm{n}_{\mathrm{T}}\right)$ is calculated as a function of both wavelength and temperature as the following equation [47]:

$$
\begin{aligned}
\mathrm{n}_{\mathrm{T}}\left(\lambda, \mathrm{T}_{\mathrm{c}}\right)= & 1.474775+\frac{6990.31}{\lambda^{2}} \\
& +\frac{2.776 \times 10^{8}}{\lambda^{4}}-\partial\left(\mathrm{T}_{\mathrm{c}}-20.15\right),
\end{aligned}
$$

where $\lambda$ is in $n m, T_{c}$ is in ${ }^{\circ} \mathrm{C}$ and $\partial$ is the thermo-optic coefficient of toluene, $\partial=3.94 \times 10^{-4} /{ }^{\circ} \mathrm{C}$. Where the toluene is very thermo-sensitive, its refractive index decreases sharply with increasing temperature. Also, it slightly decreases with increasing wavelength as clear in Fig. 2(A) Where, the melting point of toluene is $-94.9^{\circ} \mathrm{C}$ and the boiling point is $110.6{ }^{\circ} \mathrm{C}$, the range of calculations is between -80 to $80^{\circ} \mathrm{C}$. Because the thermo-optic coefficient becomes unstable when the temperature of a given material is near the melting or boiling points [47].

\subsection{Refractive Index of $\mathrm{SiO}_{2}$ and Prism}

For $\mathrm{SiO}_{2}$, the refractive index at $25^{\circ} \mathrm{C}\left(\mathrm{n}_{\mathrm{r}}\right)$ equals 1.46. Due to the change of temperature, the refractive index of it will be changed by $[60,61]$ :

$\mathrm{n}_{\mathrm{c}}(\mathrm{T})=\mathrm{n}_{\mathrm{r}}+\Delta \mathrm{n}$,
$\Delta \mathrm{n}=\gamma \mathrm{n}_{\mathrm{r}}(\Delta \mathrm{T})$, where $\gamma$ is the thermo-optic coefficient $\left(6.8 \times 10^{-6} /{ }^{\circ} \mathrm{C}\right)$, and $\Delta \mathrm{T}$ is the change in temperature [60]. Figure 2(B) shows the variation of the refractive index of $\mathrm{SiO}_{2}$ with temperature. The thermal expansion coefficient for the silicon will be neglected because it is very small. The refractive index of the used prism is 1.5 [62].

\subsection{Refractive Index of Porous Silicon $\mathbf{n}_{\mathbf{P s i}}$}

The refractive index of Silicon $\left(\mathrm{n}_{\mathrm{Si}}\right)$ in the ranges 1.2 to $14 \mu \mathrm{m}$ and $20-1600 \mathrm{~K}$ is calculated as $[63,64]$ :

$\mathrm{n}_{\mathrm{si}}^{2}\left(\lambda, \mathrm{T}_{\mathrm{K}}\right)=\varepsilon\left(\mathrm{T}_{\mathrm{K}}\right)$
$+\frac{e^{-3\left(\frac{\Delta L\left(\mathrm{~T}_{\mathrm{K}}\right)}{L_{293}}\right)}}{\lambda^{2}} x\left(0.8948+\left(4.3977 \times 10^{-4} \mathrm{~T}_{\mathrm{K}}\right)+\left(7.3835 \times 10^{-8} \mathrm{~T}_{\mathrm{K}}^{2}\right)\right)$,

where $\lambda$ in $\mu \mathrm{m}, \mathrm{T}_{\mathrm{K}}$ in $\mathrm{K}, \varepsilon\left(\mathrm{T}_{\mathrm{K}}\right)=11.4445+\left(2.7739 \times 10^{-4} \mathrm{~T}_{\mathrm{K}}\right)+$ $\left(1.7050 \times 10^{-6} \mathrm{~T}_{\mathrm{K}}{ }^{2}\right)-\left(8.1347 \times 10^{-10} \mathrm{~T}_{\mathrm{K}}{ }^{3}\right), \frac{\Delta L\left(\mathrm{~T}_{\mathrm{K}}\right)}{L_{293}}=-0.071+$ $\left(1.887 \times 10^{-6} \mathrm{~T}_{\mathrm{K}}\right)+\left(1.934 \times 10^{-9} \mathrm{~T}_{\mathrm{K}}^{2}\right)-\left(4.554 \times 10^{-13} \mathrm{~T}_{\mathrm{K}}^{3}\right)$ for $293 K \leq \mathrm{T}_{\mathrm{K}} \leq 1600 \mathrm{~K}, \frac{\Delta L\left(\mathrm{~T}_{\mathrm{K}}\right)}{L_{293}}=-0.021-\left(4.149 \times 10^{-7} \mathrm{~T}_{\mathrm{K}}\right)-$ $\left(4.620 \times 10^{-10} \mathrm{~T}_{\mathrm{K}}^{2}\right)+\left(1.482 \times 10^{-11} \mathrm{~T}_{\mathrm{K}}^{3}\right)$ for $20 \mathrm{~K} \leq \mathrm{T}_{\mathrm{K}} \leq$ $293 K$.

As cleared in Fig. 2(C), by increasing the wavelength $(\lambda)$, the refractive index of Si decreases at a constant temperature. On the contrary, by increasing the temperature, the refractive index of Si increases at a constant wavelength.

Bruggeman's effective medium approximation (BEMA) is used to calculate the refractive index of the PSi layer $\left(\mathrm{n}_{\mathrm{Psi}}\right)$ filled air as following [34, 65, 66]:

$$
\begin{aligned}
\mathrm{n}_{\mathrm{Psi}}=0.5 \sqrt{\mathcal{B}+\sqrt{\mathcal{B}^{2}+8 \mathrm{n}_{\mathrm{si}}^{2} \mathrm{n}_{\text {Air }}^{2}}}, \\
\mathcal{B}=3 \mathrm{P}\left(\mathrm{n}_{\text {Air }}^{2}-\mathrm{n}_{\mathrm{si}}^{2}\right)+\left(2 \mathrm{n}_{\mathrm{si}}^{2}-\mathrm{n}_{\text {Air }}^{2}\right),
\end{aligned}
$$

where $\mathrm{P}, \mathrm{n}_{\mathrm{Air}}, \mathrm{n}_{\mathrm{si}}$, and $\mathrm{n}_{\mathrm{PSi}}$ are the porosity ratio, the refractive index of air pores, silicon, and PSi, respectively. The refractive index of air is independent of temperature and wavelength. Figure 2(D, E) shows the refractive index of PSi as a function of temperature and wavelength at porosity $25 \%$ and $85 \%$. Compared with the toluene, the thermal expansion coefficient for the silicon will be neglected because it is very small [63]. As clear in Fig. 2(F), the effective refractive index of the whole structure decreases with the increase of both temperature and wavelength.

\subsection{Reflectance Spectra of Structure}

The structure is prism/Ag/T/C/(PSi $\left.1 / \mathrm{PSi}_{2}\right)^{\mathrm{N}} / \mathrm{Si}$. The thicknesses and porosities of the layers will be assumed as $\mathrm{d}_{\mathrm{T}}=$ 
Fig. 2 Refractive index variation of (A) Toluene, (B) $\mathrm{SiO}_{2},(\mathbf{C}) \mathrm{Si}$, (D) $\operatorname{PSi}(25 \%)$, (E) $\mathrm{PSi}(85 \%)$, and (F) $\mathrm{n}_{\text {eff }}$ of the structure at $\mathrm{d}_{\mathrm{T}}=$ $1000 \mathrm{~nm}, \mathrm{~d}_{1}=800 \mathrm{~nm}, \mathrm{~d}_{2}=$ $200 \mathrm{~nm}, \mathrm{P}_{1}=25 \%$, and $\mathrm{P}_{2}=85 \%$ as a function of temperature and wavelength
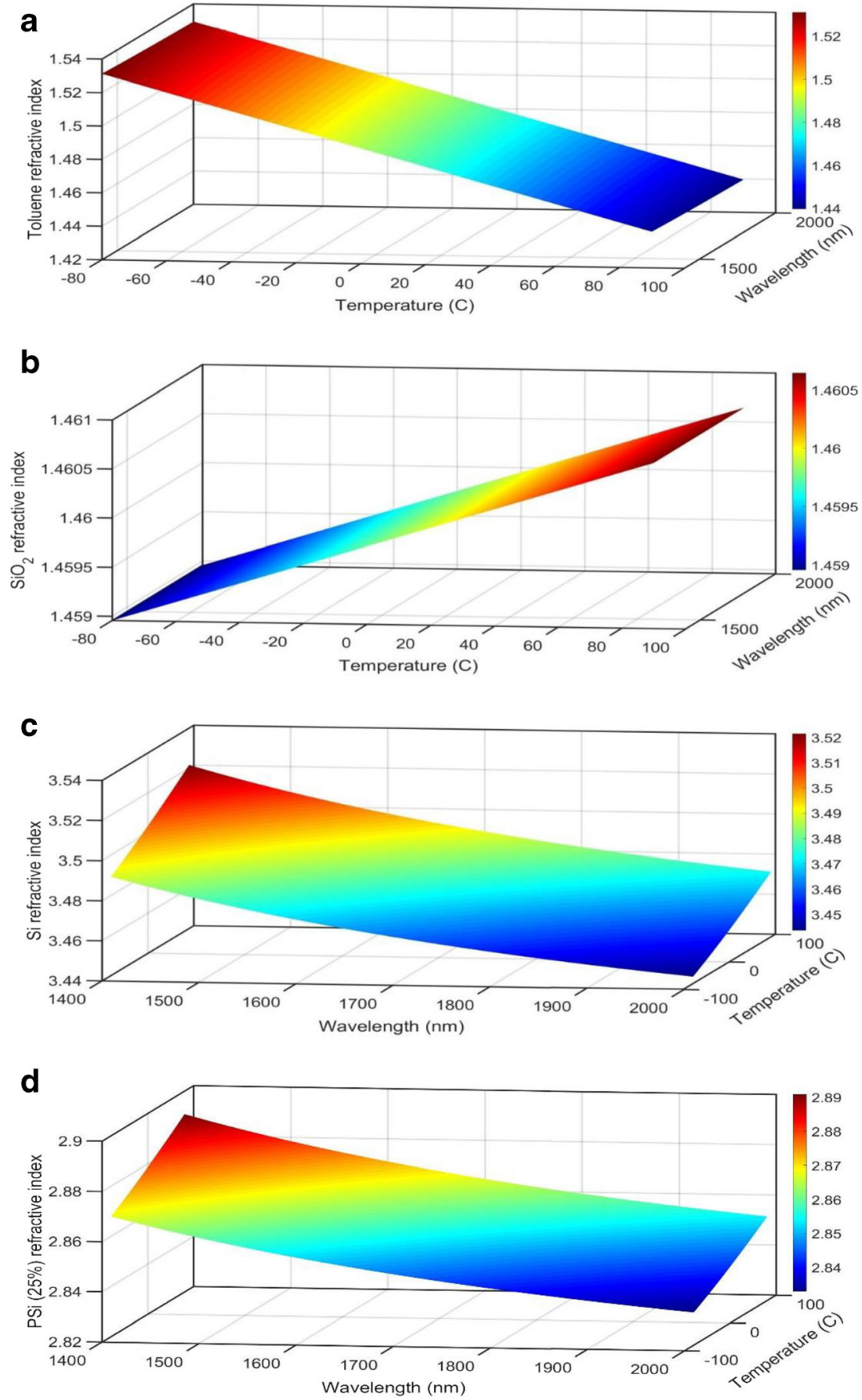

$1000 \mathrm{~nm}, \mathrm{~d}_{1}=800 \mathrm{~nm}, \mathrm{~d}_{2}=200 \mathrm{~nm}, \mathrm{P}_{1}=25 \%$, and $\mathrm{P}_{2}=85 \%$, then they will be optimized.

The thickness of the Ag layer affects only the reflectance of resonant dip, as we reported in [6]. The thickness of $30 \mathrm{~nm}$ was selected because the resonant dips have near-zero reflectance at this thickness (Fig. 3). The thickness of the $\mathrm{SiO}_{2}$ layer was selected to be small thickness $(40 \mathrm{~nm})$ because the more increase in $\mathrm{SiO}_{2}$ thickness causes a redshift in the resonant dip. As the thermo-optic coefficient of $\mathrm{SiO}_{2}$ is very small [60], the more increase in $\mathrm{SiO}_{2}$ thickness does not affect sensitivity.
Figure 3 (black curve) is the reflectance spectra as a function of the wavelength of the prism/T/C/(PSi $\left.1 / \mathrm{PSi}_{2}\right)^{\mathrm{N}} / \mathrm{Si}$ structure at a normal incident angle and $\mathrm{N}=10 . \mathrm{N}$ does not affect sensitivity as we reported in [6], but the full width at half maximum of the resonance dip (FWHM) decreases from $N=5$ to $N=10$. With more increase in $\mathrm{N}$, the FWHM seems to be constant. The number of unit cells was selected to be $\mathrm{N}=10$.

By adding an Ag layer with a thickness of $30 \mathrm{~nm}$ in front of the structure, Tamm resonance appears and makes the PBG 

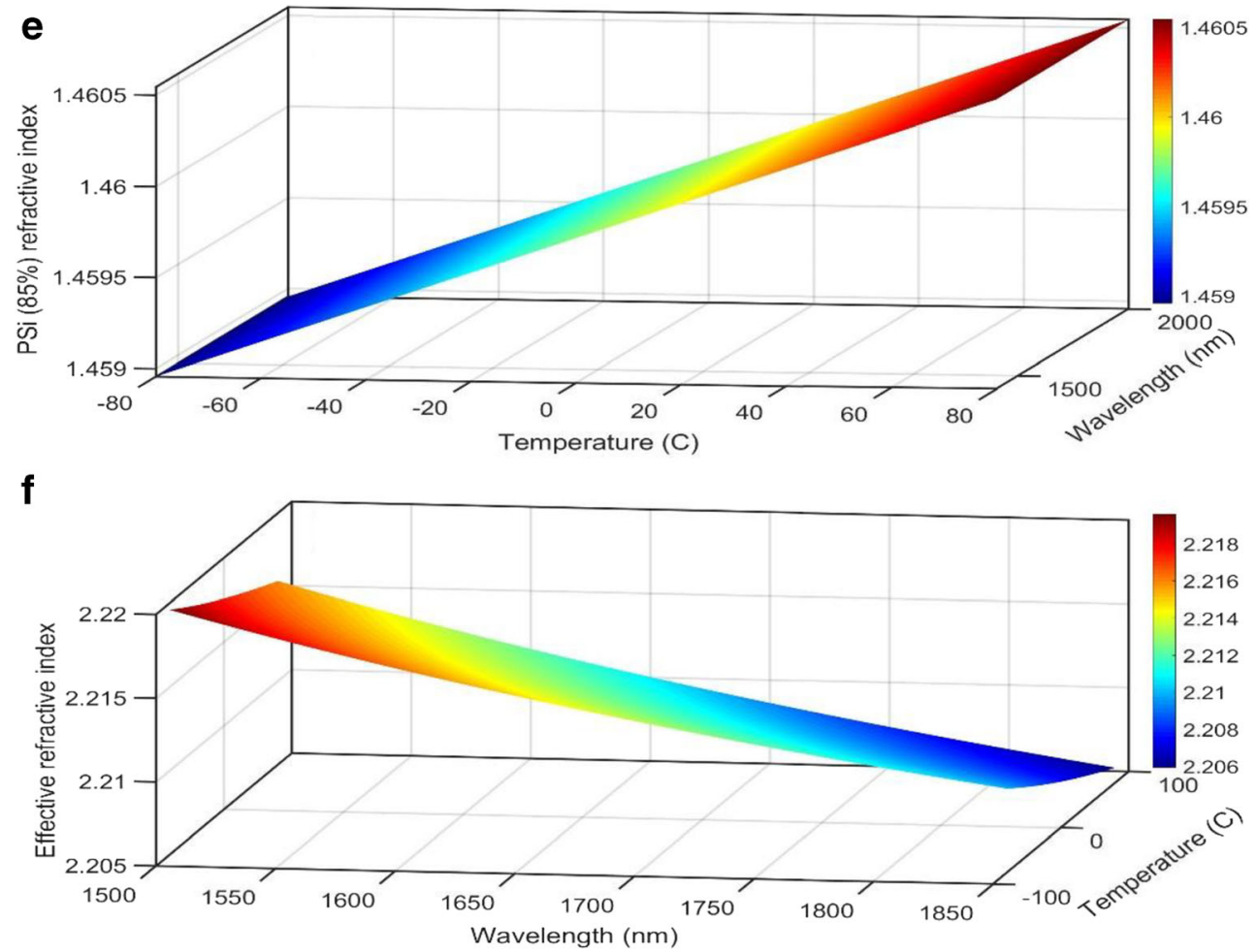

Fig. 2 (continued)

look like a complete PBG (red curve in Fig. 3). The incident light is confined between the 1D-PC (inside the bandgap region) and the metallic layer due to their high reflectance, and a strong localization occurs inside the 1D-PC [67].

Over a wavelength range, Tamm resonant dip appeared at $\lambda_{R}=1671 \mathrm{~nm}$ inside the PBG as a direct result of the confinement of electromagnetic waves between the Ag metal surface and the 1D-PC Bragg reflector [32, 34, 68].

\subsubsection{Effect of Temperature}

As the temperature increases, the refractive index of $\mathrm{PSi}_{1}$ and $\mathrm{PSi}_{2}$ increases, and the position of the PBG is redshifted because the position of the PBG depends only on the optical properties of the unit cell layers $\left(\mathrm{PSi}_{1} / \mathrm{PSi}_{2}\right)$ as cleared in Fig. 4(A).

The increase of temperature causes a sufficiently large decrease in the effective refractive index $\left(\mathrm{n}_{\text {eff }}\right)$ of the periodic structure as clear in Fig. 2(F). Consequently, the resonant dip is blue-shifted to a lower wavelength as clear in Fig. 4(B) according to BraggSnell law $[69,70]$ :

$$
\mathrm{u} \lambda_{\mathrm{R}}=2 \| \sqrt{n_{e f f}^{2}-\sin ^{2} \alpha_{0}},
$$

where $\mathrm{u}$ is the diffraction order, $\lambda_{\mathrm{R}}$ is the wavelength, $\|$ is the interplanar spacing, $\alpha_{0}$ is the incident angle, and $\mathrm{n}_{\text {eff }}$ is the effective index of refraction of the whole
Fig. 3: The reflectance spectra for prism $/ \mathrm{T} / \mathrm{SiO}_{2} / \mathrm{PSi}-1 \mathrm{DPC}$ and prism $/ \mathrm{Ag} / \mathrm{T} / \mathrm{SiO}_{2} / \mathrm{PSi}-1 \mathrm{DPC}$ as a function of the wavelength at $\mathrm{T}=0$ ${ }^{\circ} \mathrm{C}, \mathrm{d}_{\mathrm{T}}=1000 \mathrm{~nm}, \mathrm{~d}_{1}=800 \mathrm{~nm}$, $\mathrm{d}_{2}=200 \mathrm{~nm}, \mathrm{P} 1=25 \%$, and P2 $=85 \%$

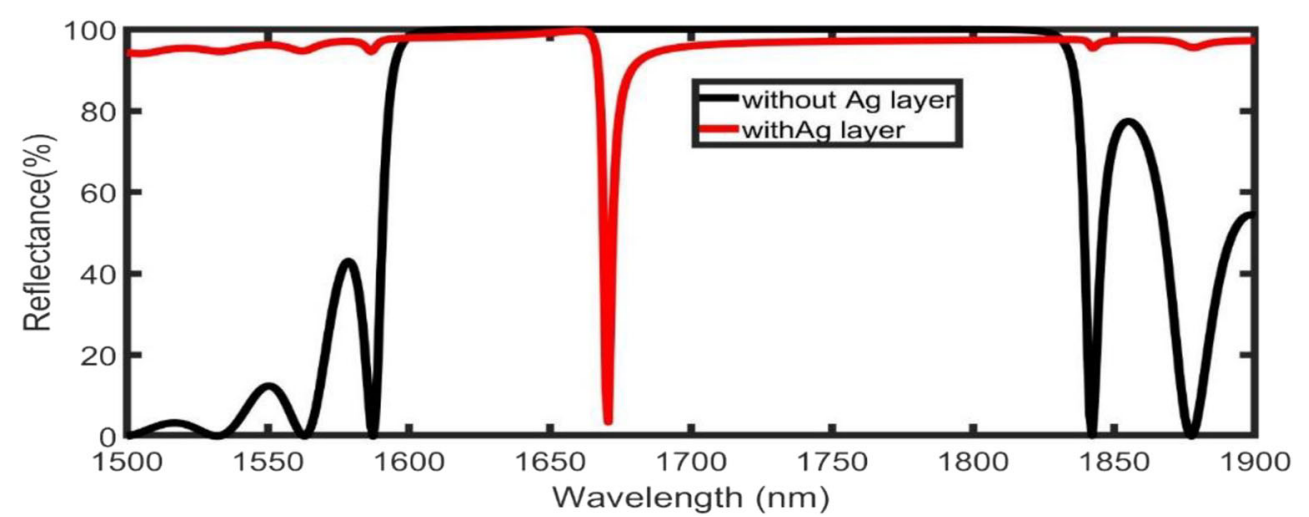


Fig. 4 The reflectance spectra for (A) $\mathrm{prism} / \mathrm{T} / \mathrm{SiO}_{2} / \mathrm{PSi}-1 \mathrm{DPC}$ as a function of the wavelength and temperature, and (B) prism/ $\mathrm{Ag} / \mathrm{T} /$ $\mathrm{SiO}_{2} / \mathrm{PSi}-1 \mathrm{DPC}$ as a function of the wavelength and temperature at a normal angle of incidence, $N=10, \mathrm{~d}_{\mathrm{C}}=40 \mathrm{~nm}$, and $\mathrm{d}_{\mathrm{m}}=$ $30 \mathrm{~nm}, \mathrm{~d}_{\mathrm{T}}=1000 \mathrm{~nm}, \mathrm{~d}_{1}=$ $800 \mathrm{~nm}, \mathrm{~d}_{2}=200 \mathrm{~nm}, \mathrm{P}_{1}=25 \%$, and $\mathrm{P}_{2}=85 \%$
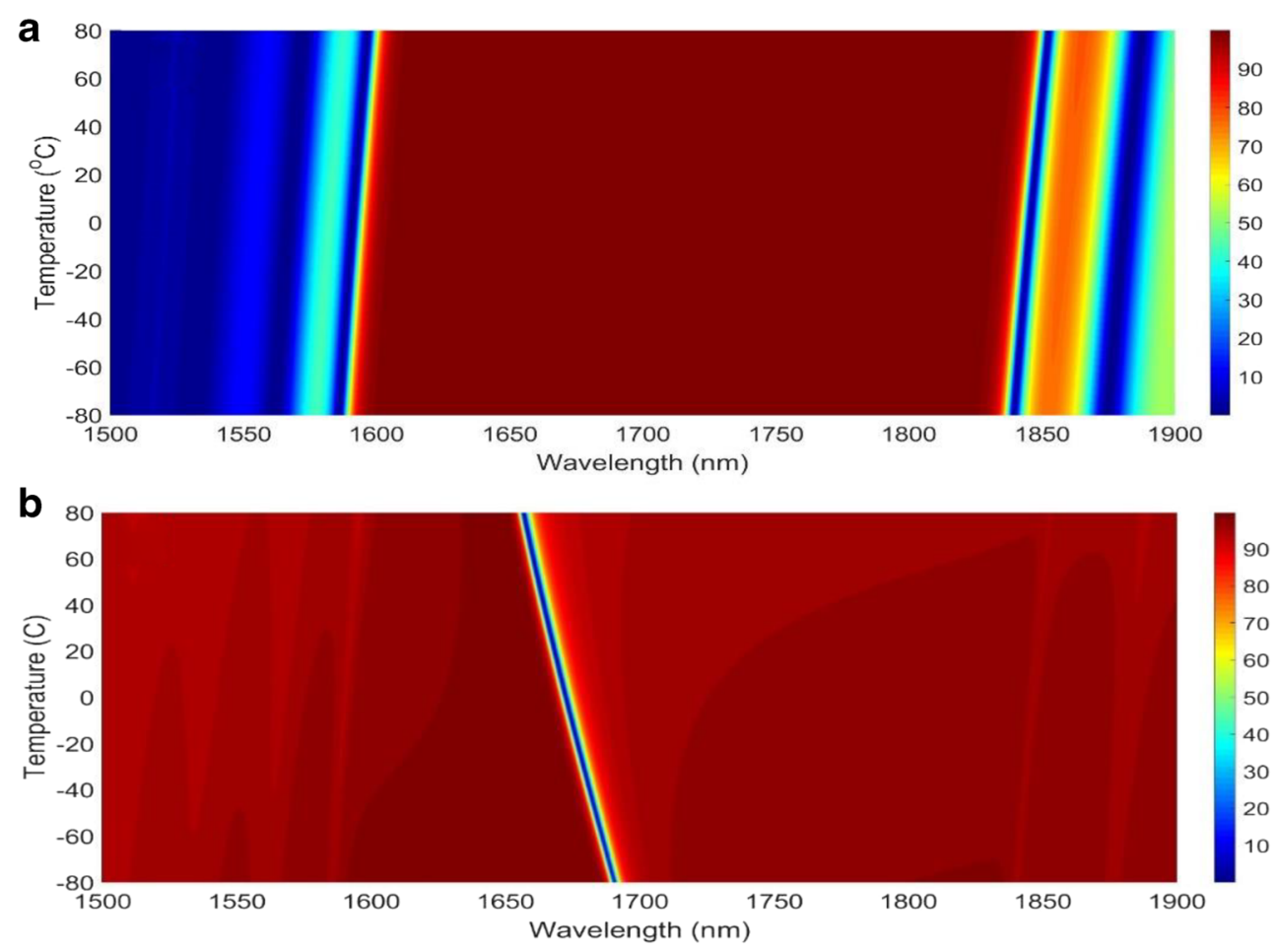

structure. By increasing the temperature, Tamm resonant dip is blue-shifted to lower wavelengths.

\subsubsection{The Effect of the Incident Angle}

According to Bragg-Snell law (Eq. 12), increasing the incident angle causes a blue shift to both PBG and resonant dip at a constant temperature as clear in Fig. 5 (A). In Fig. 5(B), by increasing the incident angle, the resonant dips at different temperatures go out from the PBG to lower wavelengths gradually and look like a negative effect on the sensitivity with the increase of the incident angle.

For the first time and in contrast to the ordinary according to the best of our knowledge $[6,39,40]$, the increase of the incident angle has a negative effect on the sensitivity of this design. This negative effect of the incident angle on the sensitivity is because the resonant dip has the highest value at the center of the PBG [71], and decreases dramatically with the approach of the resonant dip to the edge of the PBG as clear in Fig. 5 (B). Where the angle $0^{\circ}$ recorded the highest resonant dip shift in the wavelength range of concern, we will consider it as the optimum angle, and we will use it in the following study.

\subsubsection{The Effect of the Porosities of the Unit Cell Layers $\left(P_{1}\right.$ and $P_{2}$ )}

The insets of Fig. 6 elucidate the reflectance spectra as a function of both wavelength and porosities. Figure 6 (A) elucidates the reflectance spectra of the first layer $\left(\mathrm{PSi}_{1}\right)$ of the $\mathrm{PC}$-unit cell as a function of both wavelength and porosities with $N=$ $10, \mathrm{P}_{2}=85 \%, \mathrm{~d}_{\mathrm{T}}=1000 \mathrm{~nm}, \mathrm{~d}_{\mathrm{C}}=40 \mathrm{~nm}$, and $\mathrm{d}_{\mathrm{m}}=30 \mathrm{~nm}$ at $\mathrm{T}=-80{ }^{\circ} \mathrm{C}$ (green line), $\mathrm{T}=0{ }^{\circ} \mathrm{C}$ (black line), and $\mathrm{T}=80{ }^{\circ} \mathrm{C}$ (blue line). By increasing the value of $\mathrm{P}_{1}$, the width of the PBG decreases, and the resonant dip shift recorded the highest vale at $\mathrm{P}_{1}=28 \%$ at the center of the PBG. So, $\mathrm{P}_{1}=28 \%$ will be considered the optimum porosity for the $\mathrm{PSi}_{1}$ layer and will be used in the following calculations. The PBG disappeared when the porosity of the $\mathrm{PSi}_{1}$ approach to the value of the porosity of $\mathrm{PSi}_{2}(85 \%)$ because there is no refractive index contrast at this condition.

For $\mathrm{P}_{2}$, Fig. 6(B) show the reflectance spectra as a function of both wavelength and porosities of $\mathrm{PSi}_{1}$ layer with $N=10$, $\mathrm{P}_{1}=28 \%, \mathrm{~d}_{\mathrm{T}}=1000 \mathrm{~nm}, \mathrm{~d}_{\mathrm{C}}=40 \mathrm{~nm}$, and $\mathrm{d}_{\mathrm{m}}=30 \mathrm{~nm}$ at $\mathrm{T}=-$ $80{ }^{\circ} \mathrm{C}$ (green line), $\mathrm{T}=0{ }^{\circ} \mathrm{C}$ (black line), and $\mathrm{T}=80{ }^{\circ} \mathrm{C}$ (blue line). At low values of $\mathrm{P}_{2}$ (approach to the value of the porosity of $\mathrm{PSi}_{1}=28 \%$ ), there is no PBG because there is no refractive index contrast at this condition. By increasing the value of $\mathrm{P}_{2}$, the width of the PBG increases due to the increase of the refractive index contrast between the $\mathrm{PSi}_{1}$ and $\mathrm{PSi}_{2}$ layers. Besides, the resonant dip shift increased gradually from $50 \%$ to $85 \%$, then the shift seems to be constant. So, $\mathrm{P}_{2}=85 \%$ will be considered the optimum porosity for the $\mathrm{PSi}_{2}$ layer and will be used in the following calculations.

\subsubsection{The Effect of the Thicknesses $\left(d_{1}\right.$ and $\left.d_{2}\right)$}

As clear in Fig. 7, the resonant dip has the highest shift at the center of the PBG. Figure 7(A) shows that the optimum 
Fig. 5 The reflectance spectra as a function of the wavelength for (A) $\mathrm{prism} / \mathrm{T} / \mathrm{SiO}_{2} / \mathrm{PSi}-1 \mathrm{DPC}$ at $\mathrm{T}=0{ }^{\circ} \mathrm{C}$, and $(\mathbf{B})$ prism $/ \mathrm{Ag} / \mathrm{T} /$ $\mathrm{SiO}_{2} / \mathrm{PSi}-1 \mathrm{DPC}$ at $\mathrm{N}=10, \mathrm{~d}_{\mathrm{T}}=$ $1000 \mathrm{~nm}, \mathrm{~d}_{\mathrm{C}}=40 \mathrm{~nm}, \mathrm{~d}_{\mathrm{m}}=$ $30 \mathrm{~nm}$, for three different values of temperature $-80^{\circ} \mathrm{C}, 0{ }^{\circ} \mathrm{C}$, and $80{ }^{\circ} \mathrm{C}$
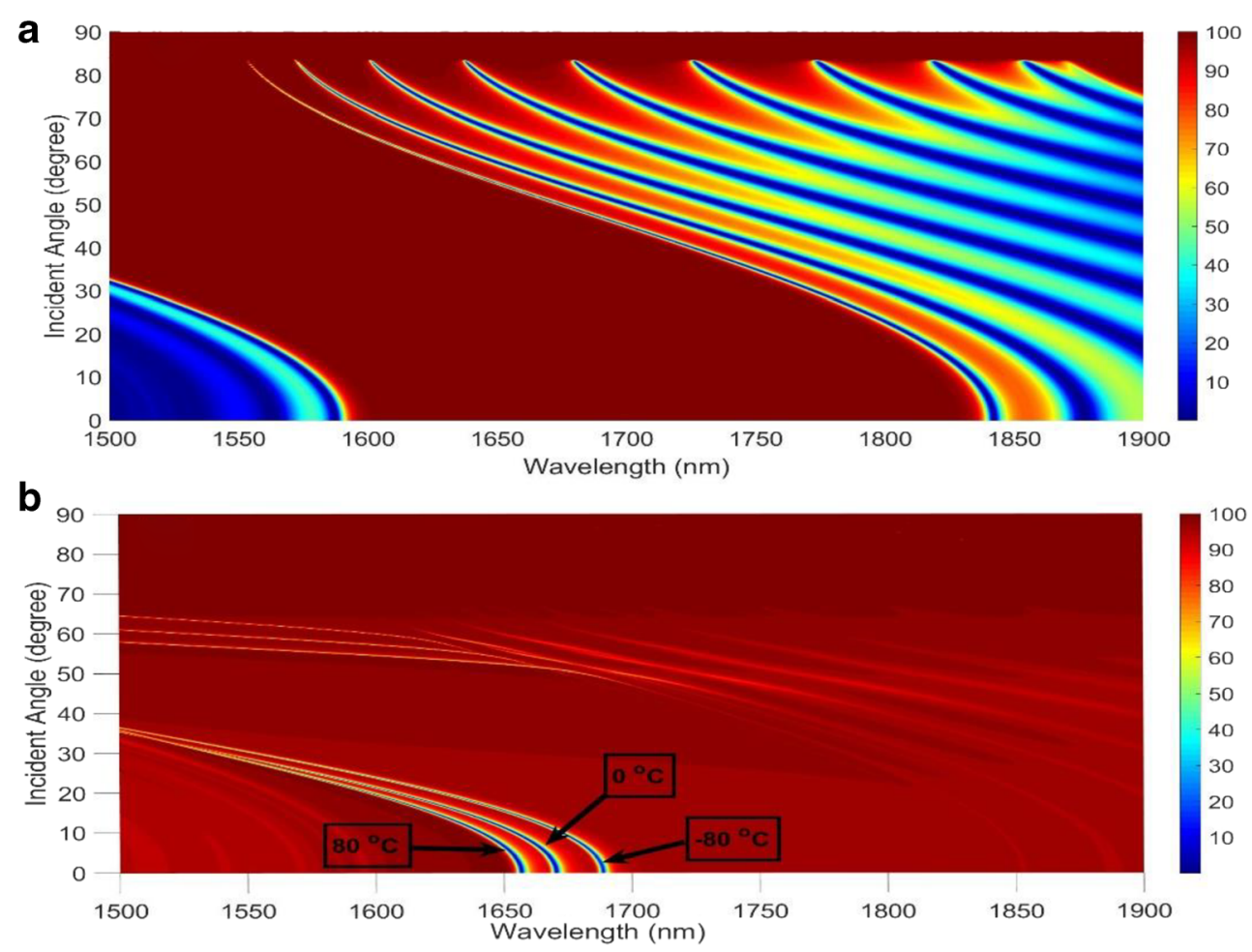

thickness of $\mathrm{d}_{1}$ is $185 \mathrm{~nm}$ that achieves $\Delta \lambda=66.18 \mathrm{~nm}$ at $\mathrm{d}_{2}=$ $200 \mathrm{~nm}, \mathrm{PSi}_{1}=28 \%$, and $\mathrm{PSi}_{2}=85 \%$. Then, the optimum thickness of $\mathrm{d}_{2}$ is $270 \mathrm{~nm}$ that achieves $\Delta \lambda=67.74 \mathrm{~nm}$ using previous optimum conditions $\left(\mathrm{d}_{1}=185 \mathrm{~nm}, \mathrm{PSi}_{1}=28 \%\right.$, and $\left.\mathrm{PSi}_{2}=85 \%\right)$ as clear in Fig. 7(B).

\subsubsection{The Effect of the Toluene Layer Thickness}

The increase of the toluene layer thickness does not influence the PBG as cleared in Fig. 8(A) because the toluene layer is outside the periodic structure. By contrast, in the presence of
Fig. 6 The reflectance spectra as a function of both wavelength and porosities $\left(\mathrm{P}_{1}\right.$ and $\left.\mathrm{P}_{2}\right)$ of prism/T/ $\mathrm{SiO}_{2} / \mathrm{PSi}-1 \mathrm{DPC}$ with $\mathrm{N}=10$, $\mathrm{d}_{\mathrm{T}}=1000 \mathrm{~nm}, \mathrm{~d}_{\mathrm{C}}=40 \mathrm{~nm}, \mathrm{~d}_{\mathrm{m}}=$ $30 \mathrm{~nm}$ at $\mathrm{T}=-80{ }^{\circ} \mathrm{C}$ (green line), $\mathrm{T}=0{ }^{\circ} \mathrm{C}$ (black line), and $\mathrm{T}=$ $80{ }^{\circ} \mathrm{C}$ (blue line) (A) $\mathrm{P}_{1}$ with assuming $\mathrm{P}_{2}=85 \%$, and (B) $\mathrm{P}_{2}$ with using the optimum value of $\mathrm{P}_{1}=28 \%$

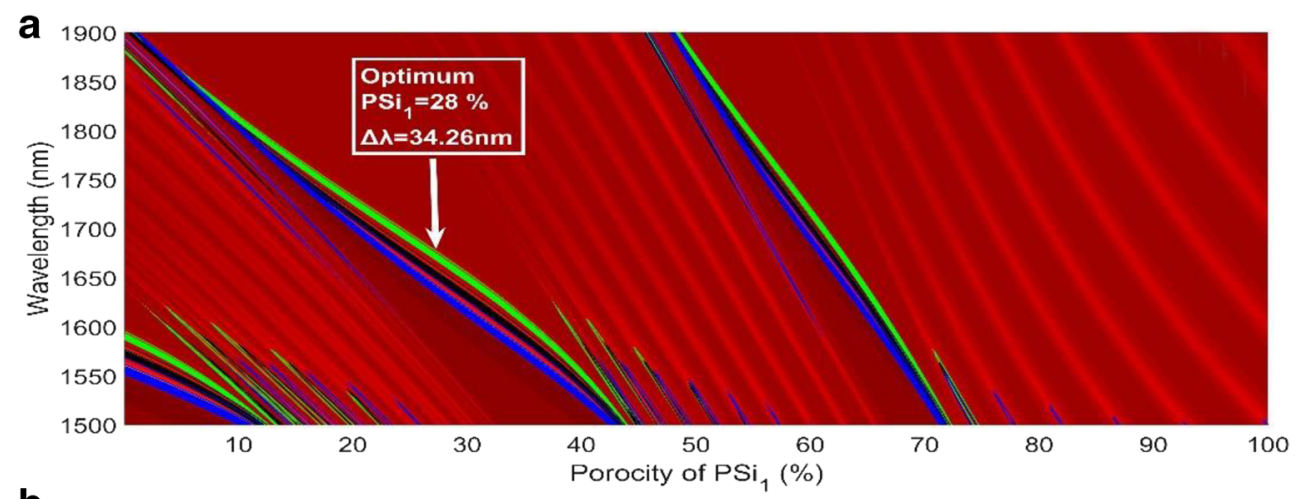

\section{b}

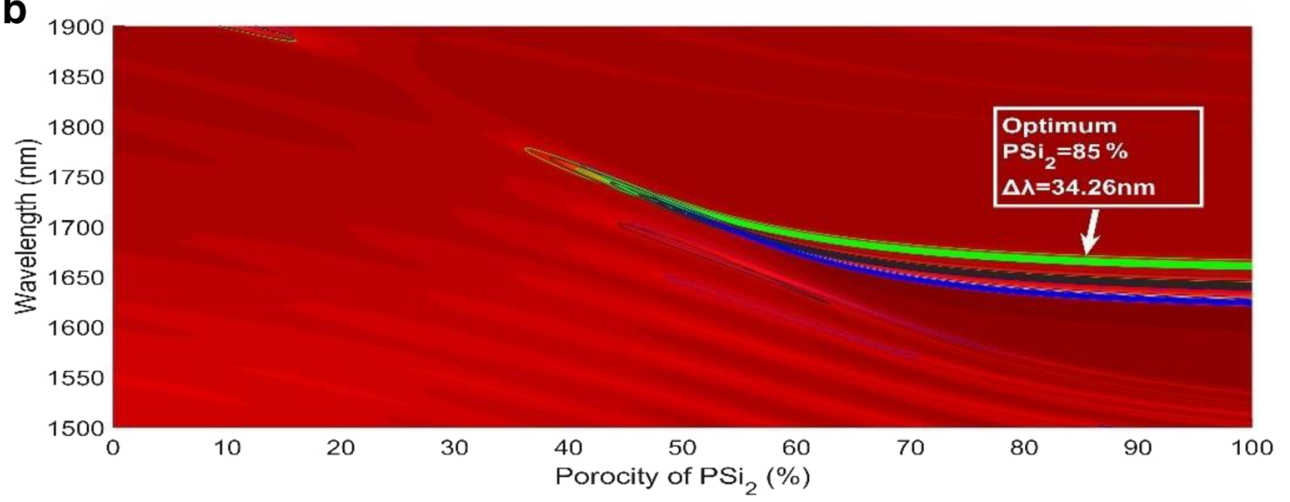


Fig. 7 The reflectance spectra as a function of both wavelength and thickness $\left(\mathrm{d}_{1}\right.$ and $\left.\mathrm{d}_{2}\right)$ of prism/T/ $\mathrm{SiO}_{2} / \mathrm{PSi}-1 \mathrm{DPC}$ with $\mathrm{N}=10$, $\mathrm{d}_{\mathrm{T}}=1000 \mathrm{~nm}, \mathrm{~d}_{\mathrm{C}}=40 \mathrm{~nm}, \mathrm{~d}_{\mathrm{m}}=$ $30 \mathrm{~nm}$ at $\mathrm{T}=-80{ }^{\circ} \mathrm{C}$ (green line), $\mathrm{T}=0{ }^{\circ} \mathrm{C}$ (black line), and $\mathrm{T}=$ $80^{\circ} \mathrm{C}$ (blue line) (A) $\mathrm{d}_{1}$ with assuming $\mathrm{d}_{2}=200 \mathrm{~nm}$, and (B) $\mathrm{d}_{2}$ with using the optimum value of $\mathrm{d}_{1}=185 \mathrm{~nm}$

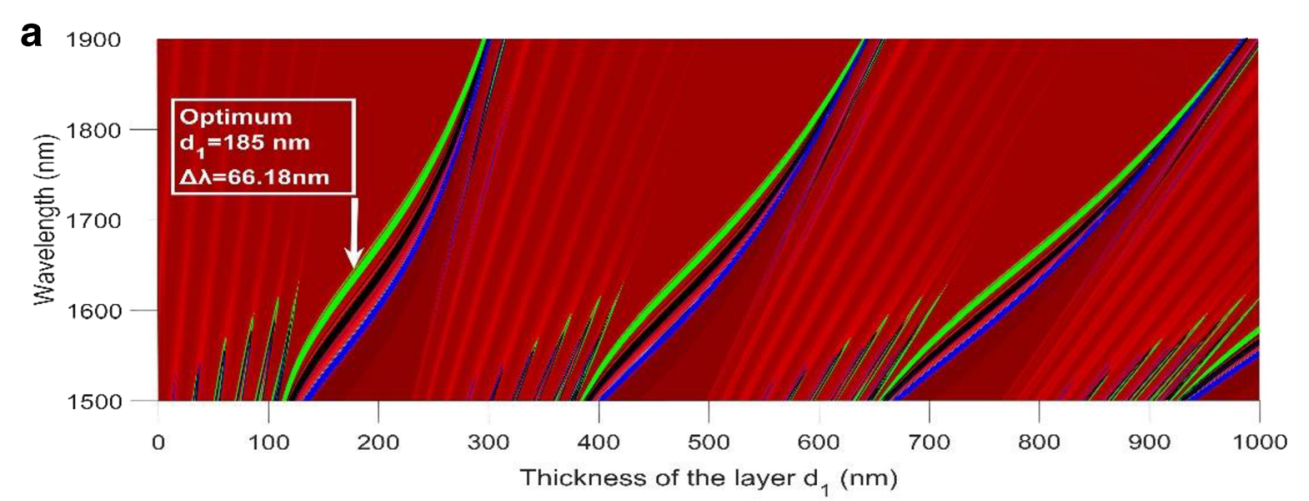

b

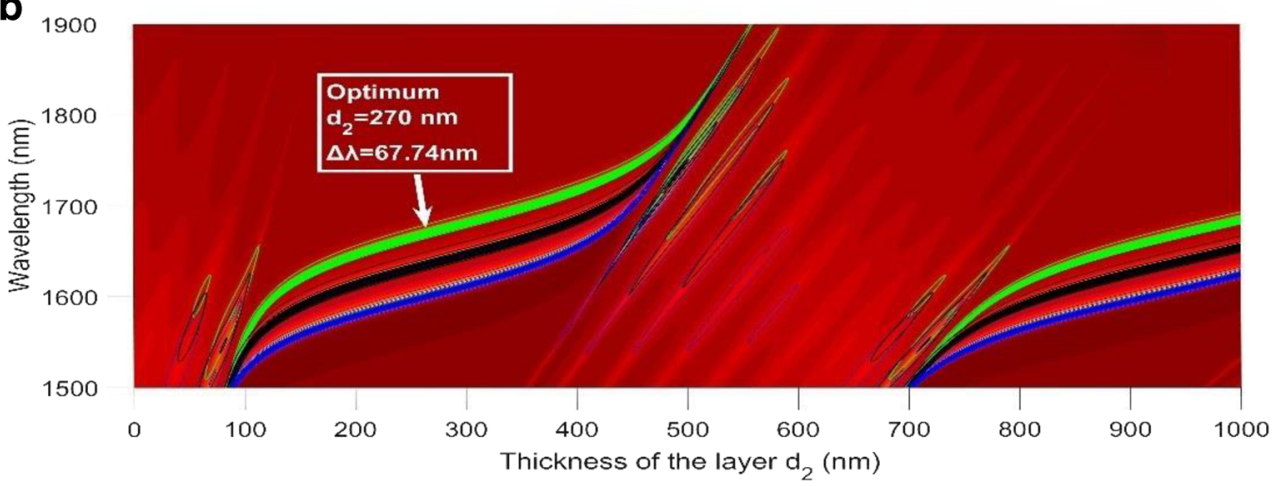

the Ag layer, changing the toluene layer causes a drastic change in the Tamm resonance conditions, and increases the radiation confinement, which makes it very sensitive to temperature. Figure 8(B) shows that the resonant dip shift increases with the increase of the wavelength and the increase of toluene layer thickness due to the increase of the optical path through the toluene with the increase of its thickness. High confinement of electromagnetic waves occurs with the increase of the optical path length. We will consider the thickness of $10,795 \mathrm{~nm}$ as the optimum toluene thickness because the resonant dips will overlap with each other at thicknesses higher than $10,795 \mathrm{~nm}$.

\subsection{Sensor Analysis at the Optimum Conditions}

The optimum conditions of the proposed sensor are $\alpha_{0}=0^{\circ}, \mathrm{N}=$ $10, \mathrm{~d}_{\mathrm{T}}=10,795 \mathrm{~nm}, \mathrm{~d}_{\mathrm{C}}=40 \mathrm{~nm}$, and $\mathrm{d}_{\mathrm{m}}=30 \mathrm{~nm}, \mathrm{~d}_{1}=185 \mathrm{~nm}$, $\mathrm{d}_{2}=270 \mathrm{~nm}, \mathrm{PSi}_{1}=28 \%$ and $\mathrm{PSi}_{2}=85 \%$. As clear in Fig. 8(C), the resonant dip is blue-shifted from $2193.6 \mathrm{~nm}$ to $2082.3 \mathrm{~nm}$ with the increase of temperature from $-80^{\circ} \mathrm{C}$ to $80^{\circ} \mathrm{C}$.

To assess the performance of the proposed sensor, different parameters will be calculated such as sensitivity, signal-tonoise (SNR), resolution (RS), Q-factor, and detection limit (LOD). The sensitivity is calculated as the following [72]:

$$
S=\frac{\Delta \lambda_{R}}{\Delta \mathrm{T}}
$$

where $\Delta \lambda_{R}$ is the resonance wavelength shift $\left(\Delta \lambda_{R}=\lambda_{T 2}\right.$ $\left.-\lambda_{\mathrm{T} 1}\right)$, and $\Delta \mathrm{T}$ is the Temperature difference $\left(\Delta \mathrm{T}=\mathrm{T}_{2}-\right.$
$\mathrm{T}_{1}$ ). The second parameter is signal-to-noise (SNR) that is calculated by $[40]$ :

$\mathrm{SNR}=\frac{\Delta \lambda_{\mathrm{R}}}{\mathrm{FWHM}}$

The third parameter is the resolution(RS) of the suggested sensor which reflects the smallest change in the resonant dip that can be measured accurately by [40]:

$\mathrm{RS}=\frac{2(\mathrm{FWHM})}{3(\mathrm{SNR})^{1 / 4}}$

The quality factor of the proposed sensor is calculated as:

$\mathrm{Q}=\frac{\lambda_{\mathrm{R}}}{\mathrm{FWHM}}$

This proposed sensor showed a significantly lower detection limit $\left(\mathrm{DL}=10^{-1}\right)$ that can be calculated by $[73,74]$ :

$\mathrm{LOD}=\frac{\lambda_{\mathrm{R}}}{20 \mathrm{SQ}}$.

Table 1 shows that the proposed sensor has high sensitivity $\left(0.7 \mathrm{~nm} /{ }^{\circ} \mathrm{C}\right)$, high $\operatorname{SNR}(\sim 30)$, and very low RS $(\sim 0.25)$ which makes it very distinguished compared to previous works as cleared in Table 2. Figure 6(C) shows the reflectance spectra of the sensor at optimum conditions for different values of temperatures. 
Fig. 8 The reflectance spectra at $\alpha_{0}=0^{\circ}, \mathrm{N}=10, \mathrm{~d}_{\mathrm{C}}=40 \mathrm{~nm}$, $\mathrm{d}_{\mathrm{m}}=30 \mathrm{~nm}, \mathrm{~d}_{1}=185 \mathrm{~nm}, \mathrm{~d}_{2}=$ $270 \mathrm{~nm}, \mathrm{PSi}_{1}=28 \%$ and $\mathrm{PSi}_{2}=$ $85 \%$ for $(\mathbf{A})$ prism $/ \mathrm{T} / \mathrm{SiO}_{2} / \mathrm{PSi}$ 1DPC as a function of the wavelength and toluene layer thickness at $\mathrm{T}=-80{ }^{\circ} \mathrm{C},(\mathbf{B})$ prism $/ \mathrm{Ag} / \mathrm{T} / \mathrm{SiO}_{2} / \mathrm{PSi}-1 \mathrm{DPC}$ as a function of the wavelength and toluene layer thickness at $\mathrm{T}=$ $80^{\circ} \mathrm{C}$ (green line), $\mathrm{T}=0^{\circ} \mathrm{C}$ (black line), and $\mathrm{T}=80^{\circ} \mathrm{C}$ (blue line), and (C) prism $/ \mathrm{Ag} / \mathrm{T} / \mathrm{SiO}_{2} /$ PSi-1DPC as a function of the wavelength, at $\mathrm{d}_{\mathrm{T}}=10,795 \mathrm{~nm}$

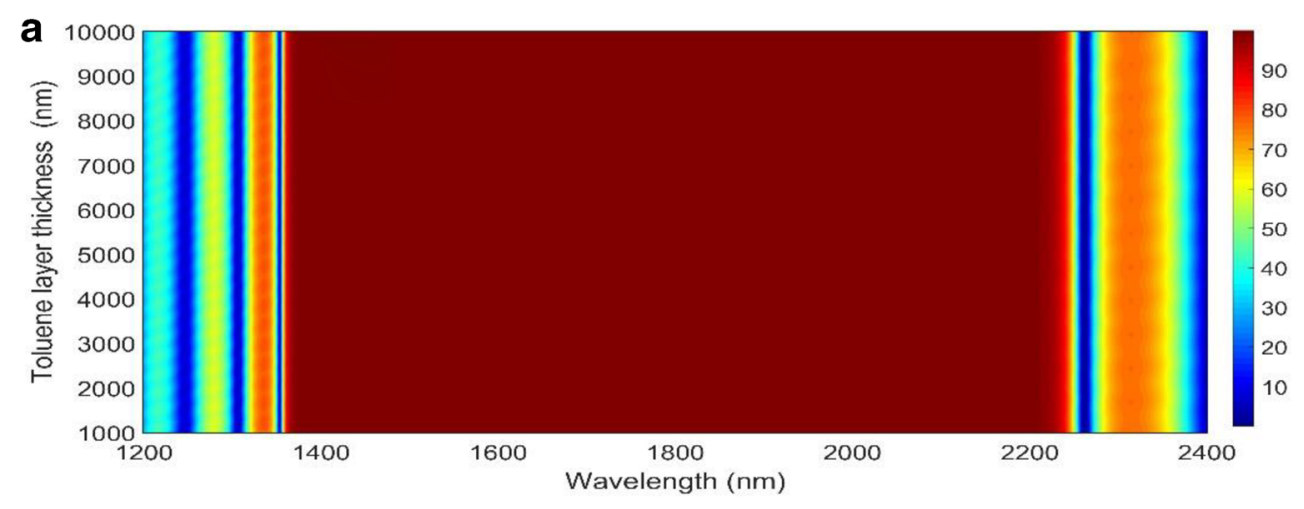

b

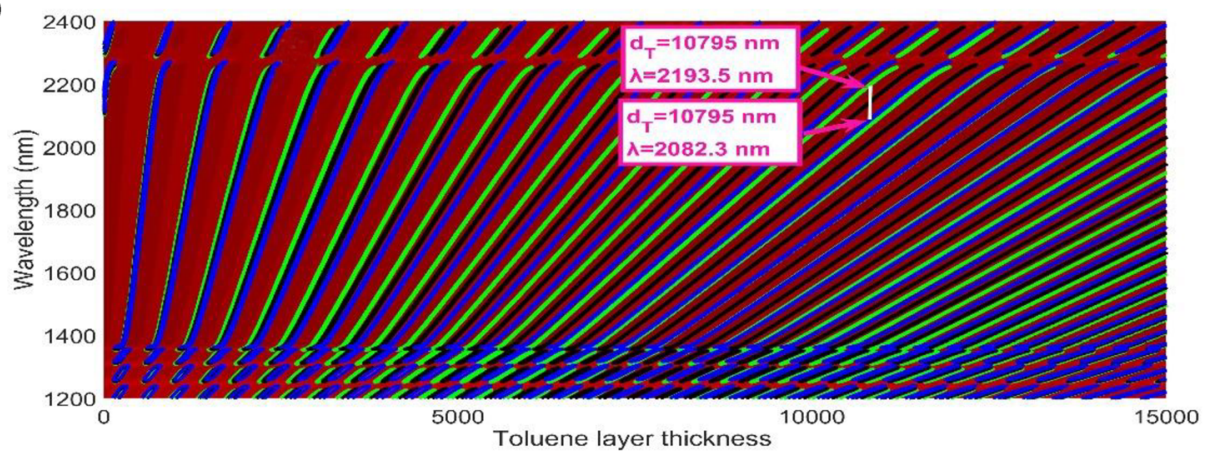

C

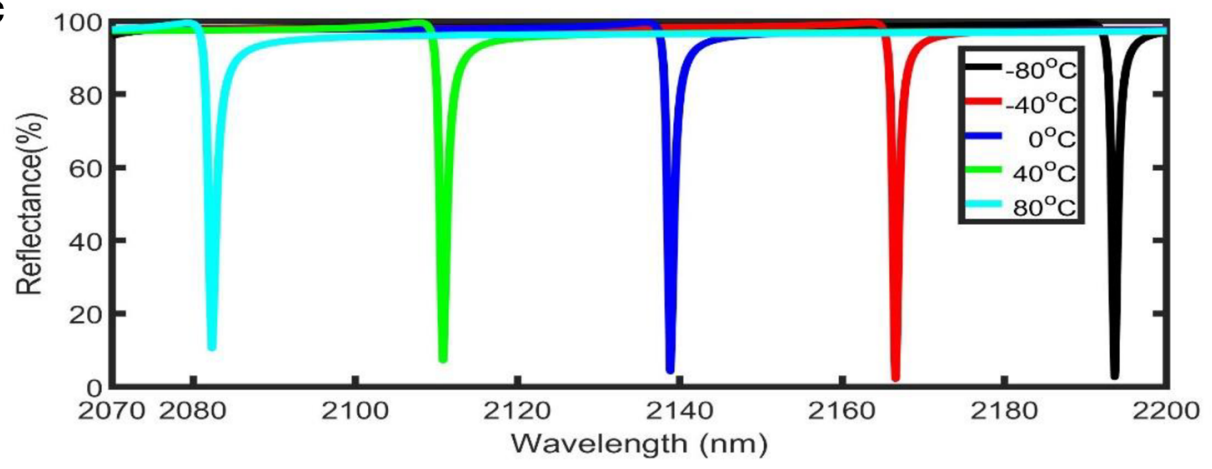

\section{Conclusion}

In summary, we suggested a high-sensitivity temperature sensor based on Tamm resonance in a silver-coated multilayer of mesoporous Si. The optimization process showed a negative effect on the increase of the incident angle and a positive effect on the increase of the thickness of the toluene layer on the performance of the proposed sensor. It recorded high sensitivity $\left(0.7 \mathrm{~nm} /{ }^{\circ} \mathrm{C}\right)$, high $\mathrm{SNR}(\sim 30)$, and very low resolution $(\sim 0.25)$ for temperature sensing that makes it very distinguished compared to previous works. The proposed design may help in the correct handling of infectious substances and can be used as a narrow-band filter under temperature effects.
Table 1 Sensor parameters for different values of temperature at the optimum conditions

\begin{tabular}{lllllllll}
\hline $\mathrm{T}\left({ }^{\circ} \mathrm{C}\right)$ & $\begin{array}{l}\lambda_{\mathrm{R}} \\
(\mathrm{nm})\end{array}$ & $\Delta \lambda_{\mathrm{R}}(\mathrm{nm})$ & $\begin{array}{l}\mathrm{S} \\
\left(\mathrm{nm} /{ }^{\circ} \mathrm{C}\right)\end{array}$ & FWHM (nm) & SNR & RS & $\begin{array}{l}\text { Q- } \\
\text { factor }\end{array}$ & LOD \\
\hline 80 & 2082.3 & - & - & 1.133 & - & - & 1837.9 & - \\
40 & 2110.8 & 28.5 & 0.713 & 1.024 & 27.8 & 0.3 & 2061.3 & 0.07 \\
0 & 2138.8 & 28.0 & 0.7 & 0.919 & 30.5 & 0.3 & 2327.3 & 0.07 \\
-40 & 2166.6 & 27.8 & 0.695 & 0.836 & 33.3 & 0.2 & 2591.6 & 0.06 \\
-80 & 2193.6 & 27.0 & 0.675 & 0.811 & 33.3 & 0.2 & 2706.5 & 0.06 \\
\hline
\end{tabular}


Table 2 Comparison of sensitivity and the dynamic range of the proposed structure with other temperature sensors in the literature $(\mathrm{NC}=$ not counted $)$

\begin{tabular}{llllll}
\hline Reference & $\mathrm{S}\left(\mathrm{nm} /{ }^{\circ} \mathrm{C}\right)$ & $\mathrm{SNR}$ & $\mathrm{RS}$ & $\mathrm{LOD}$ & operating range $\left({ }^{\circ} \mathrm{C}\right)$ \\
\hline$[75], 2012$ & 0.07 & $\mathrm{NC}$ & $\mathrm{NC}$ & $\mathrm{NC}$ & 20 to 70 \\
{$[25], 2013$} & 0.07 & $\mathrm{NC}$ & $\mathrm{NC}$ & $\mathrm{NC}$ & 0 to 527 \\
{$[26], 2018$} & 0.06 & $\mathrm{NC}$ & $\mathrm{NC}$ & $\mathrm{NC}$ & 25 to 170 \\
{$[27], 2019$} & 0.27 & $\mathrm{NC}$ & $\mathrm{NC}$ & $\mathrm{NC}$ & -40 to 40 \\
{$[28], 2019$} & 0.06 & $\mathrm{NC}$ & $\mathrm{NC}$ & $\mathrm{NC}$ & 5 to 540 \\
{$[76], 2019$} & 0.24 & $\mathrm{NC}$ & $\mathrm{NC}$ & 0.004 to 0.006 & 20 to 60 \\
This work & 0.70 & $\sim 30$ & $\sim 0.25$ & 0.06 to 0.07 & -80 to 80 \\
\hline
\end{tabular}

Acknowledgments The author thanks the reviewers and editors for improving this article.

Author Contributions Z.A. Zaky invented the original idea for the study, implemented the computer code, performed the numerical simulations, analyzed the data, and wrote the main manuscript text. A.M. Ahmed discussed the data. A.H. Aly discussed the results and supervised this work. All Authors developed the final manuscript.

Data Availability Requests for materials or code should be addressed to Z.A.Z.

\section{Declarations}

Ethics Declarations This article does not contain any studies involving animals or human participants performed by any of the authors.

Consent to Participate Not Applicable.

Consent for Publication Not Applicable.

Disclosures The authors declare no conflicts of interest.

\section{References}

1. Wang X-d, Wolfbeis OS, Meier RJ (2013) Luminescent probes and sensors for temperature. Chem Soc Rev 42:7834-7869

2. Ćirić A, Stojadinović S, Dramićanin MD (2020) Luminescence temperature sensing using thin-films of undoped $\mathrm{Gd} 2 \mathrm{O} 3$ and doped with $\mathrm{Ho} 3+$, Eu3+, and Er3+ prepared by plasma electrolytic oxidation. Ceram Int 46:23223-23231

3. W. H. Organization, "Laboratory testing for coronavirus disease 2019 (COVID-19) in suspected human cases: interim guidance, 2 March 2020," World Health Organization 2020

4. Yablonovitch E (1987) Inhibited spontaneous emission in solidstate physics and electronics. Phys Rev Lett 58:2059-2062

5. Shaban SM, Mehaney A, Aly AH (2020) Determination of 1propanol, ethanol, and methanol concentrations in water based on a one-dimensional phoxonic crystal sensor. Appl Opt 59:38783885

6. Zaky ZA, Ahmed AM, Shalaby AS, Aly AH (2020) Refractive index gas sensor based on the Tamm state in a one-dimensional photonic crystal: theoretical optimisation. Sci Rep 10:9736

7. Aly AH, Zaky ZA (2019) Ultra-sensitive photonic crystal cancer cells sensor with a high-quality factor. Cryogenics 104:102991

8. Aly AH, Mohamed D, Mohaseb MA, El-Gawaad NSA, Trabelsi Y (2020) Biophotonic sensor for the detection of creatinine concentration in blood serum based on 1D photonic crystal. RSC Adv 10:31765-31772

9. Nouman WM, Abd El-Ghany S, Sallam SM, Dawood AFB, Aly AH (2020) "Biophotonic sensor for rapid detection of brain lesions using 1D photonic crystal," OPTICAL AND QUANTUM ELECTRONICS, 52

10. Qiu M, Jaskorzynska B (2003) Design of a channel drop filter in a two-dimensional triangular photonic crystal. Appl Phys Lett 83: 1074-1076

11. Aly AH, Ameen AA, Vigneswaran D (2019) Superconductor nanometallic photonic crystals as a novel smart window for lowtemperature applications. J Supercond Nov Magn 32:191-197

12. Gao S, Dou Y, Li Q, Jiang X (2017) Tunable photonic crystal lens with high sensitivity of refractive index. Opt Express 25:71127120

13. Aly AH, Sayed H, Elsayed HA (2019) Development of the monolayer silicon solar cell based on photonic crystals. Silicon 11:13771382

14. Suthar B, Bhargava A (2020) Pressure sensor based on Quantum well-structured photonic crystal, Silicon, 1-4

15. Zegadi R, Ziet L, Zegadi A (2019) Design of High Sensitive Temperature Sensor Based on two-dimensional photonic crystal, Silicon, 1-7

16. Zaky ZA, Aly AH (2020) Theoretical study of a tunable lowtemperature photonic crystal sensor using dielectricsuperconductor Nanocomposite layers. J Supercond Nov Magn 33:2983-2990

17. Abd El-Ghany SE, Noum WM, Matar Z, Zaky ZA, Aly AH (2020) Optimized bio-photonic sensor using 1D-photonic crystals as a blood hemoglobin sensor. Phys Scr 96:035501

18. Abadla MM, Elsayed HA, Mehaney A (2020) Novel Design for the Temperature Sensing Using Annular Photonic Crystals, Silicon, 1-9

19. SenS, Hasan MM, Ahmed K (2020) Ultra-low material loss quasi pattern based photonic crystal Fiber for long distance $\mathrm{THz}$ wave propagation, Silicon, 1-11

20. Mehedi ST, Shamim AAM, Paul BK, Ahmed K (2020) Graphene injected D-shape photonic crystal fiber for nonlinear optical applications. Silicon 12:2293-2300

21. Alwan AM, Abbas RA, Dheyab AB (2018) Study the characteristic of planer and sandwich PSi gas sensor (comparative study). Silicon 10:2527-2534

22. Chen H, Xi N, Song B, Chen L, Zhao J, Lai KWC et al (2012) Infrared camera using a single nano-photodetector. IEEE Sensors J 13:949-958

23. Pashazadeh P, Mokhtarzadeh A, Hasanzadeh M, Hejazi M, Hashemi M, de la Guardia M (2017) Nano-materials for use in sensing of salmonella infections: recent advances. Biosens Bioelectron 87:1050-1064

24. Aly AH, Sayed FA (2020) THz cutoff frequency and multifunction $\mathrm{Ti}_{2} \mathrm{Ba}_{2} \mathrm{Ca}_{2} \mathrm{Cu}_{3} \mathrm{O}_{10} / \mathrm{GaAs}$ photonic bandgap materials. International Journal of Modern Physics B 34:2050091 
25. Srivastava T, Das R, Jha R (2013) Highly sensitive plasmonic temperature sensor based on photonic crystal surface plasmon waveguide. Plasmonics 8:515-521

26. Geng Y, Wang L, Tan X, Xu Y, Hong X, Li X (2018) A compact four-wave mixing-based temperature Fiber sensor with partially filled photonic crystal Fiber. IEEE Sensors J 19:2956-2961

27. Chen J, Zhang H, Liu G, Liu J, Liu Y, Tang L, Liu Z (2019) Highquality temperature sensor based on the plasmonic resonant absorber. Plasmonics 14:279-283

28. Rajasekar R, Robinson S (2019) Nano-pressure and temperature sensor based on hexagonal photonic crystal ring resonator. Plasmonics 14:3-15

29. Kumar S, Maji PS, Das R (2017) Tamm-plasmon resonance-based temperature sensor in a $\mathrm{Ta}_{2} \mathrm{O}_{5} / \mathrm{SiO}_{2}$ based distributed Bragg reflector. Sensors Actuators A Phys 260:10-15

30. Shen H, Wang Z, Wu Y, Yang B (2016) One-dimensional photonic crystals: fabrication, responsiveness and emerging applications in 3D construction. RSC Adv 6:4505-4520

31. Auguié B, Bruchhausen A, Fainstein A (2015) Critical coupling to Tamm plasmons. J Opt 17:035003

32. Kumar S, Shukla MK, Maji PS, Das R (2017) Self-referenced refractive index sensing with hybrid-Tamm-plasmon-polariton modes in sub-wavelength analyte layers. J Phys D Appl Phys 50: 375106

33. Kee C-S, Kim J-E, Park HY, Lim H (1999) Roles of wave impedance and refractive index in photonic crystals with magnetic and dielectric properties. IEEE transactions on microwave theory and techniques 47:2148-2150

34. Ahmed AM, Mehaney A (2019) Ultra-high sensitive 1D porous silicon photonic crystal sensor based on the coupling of Tamm/Fano resonances in the mid-infrared region. Sci Rep 9:6973

35. Pacholski C (2013) Photonic crystal sensors based on porous silicon. Sensors 13:4694-4713

36. Wang Z, Zhang J, Xu S, Wang L, Cao Z, Zhan P, Wang Z (2007) 1D partially oxidized porous silicon photonic crystal reflector for mid-infrared application. J Phys D Appl Phys 40:4482-4484

37. Zaky ZA, Aly AH (2021) Modeling of a biosensor using Tamm resonance excited by graphene. Appl Opt 60:1411-1419

38. Jabbar AA, Alwan AM, Zayer MQ, Bohan AJ (2020) Efficient single cell monitoring of pathogenic bacteria using bimetallic nanostructures embedded in gradient porous silicon. Mater Chem Phys 241:122359

39. Aly AH, Zaky ZA, Shalaby AS, Ahmed AM, Vigneswaran D (2019) Theoretical study of hybrid multifunctional onedimensional photonic crystal as a flexible blood sugar sensor, Physica Scripta, 95

40. Abadla MM, Elsayed HA (2020) Detection and sensing of hemoglobin using one-dimensional binary photonic crystals comprising a defect layer. Appl Opt 59:418-424

41. Herino R, Bomchil G, Barla K, Bertrand C, Ginoux JL (1987) Porosity and pore size distributions of porous silicon layers. J Electrochem Soc 134:1994-2000

42. Jane A, Dronov R, Hodges A, Voelcker NH (2009) Porous silicon biosensors on the advance. Trends Biotechnol 27:230-239

43. Rea I (2008) POROUS SILICON BASED OPTICAL DEVICES FOR BIOCHEMICAL SENSING, UNIVERSITY OF NAPLES "FEDERICO II

44. Xi J-Q, Ojha M, Cho W, Plawsky J, Gill W, Gessmann T et al (2005) Omnidirectional reflector using nanoporous $\mathrm{SiO}_{2}$ as a lowrefractive-index material. Opt Lett 30:1518-1520

45. Hu DJJ, Ho HP (2017) Recent advances in plasmonic photonic crystal fibers: design, fabrication and applications. Adv Opt Photon 9:257-314

46. Ahmed AM, Shaban $\mathrm{M}$ (2020) Highly sensitive au- $\mathrm{Fe}_{2} \mathrm{O}_{3}-\mathrm{au}$ and $\mathrm{Fe}_{2} \mathrm{O}_{3}-\mathrm{au}-\mathrm{Fe}_{2} \mathrm{O}_{3}$ biosensors utilizing strong surface plasmon resonance. Applied Physics B 126:1-10
47. Ma J, Yu H, Jiang X, Jiang D (2017) High-performance temperature sensing using a selectively filled solid-core photonic crystal fiber with a central air-bore. Opt Express 25:9406-9415

48. Acikgoz S, Sarpkaya I, Milas P, Inci MN, Demirci G, Sanyal R (2011) Investigation of fluorescence dynamics of BODIPY embedded in porous silicon and monitoring formation of a $\mathrm{SiO} 2$ layer via a confocal FLIM-based NSET method. J Phys Chem C 115:2218622190

49. Kasztelanic R, Anuszkiewicz A, Stepniewski G, Filipkowski A, Ertman S, Pysz D et al (2018) All-normal dispersion supercontinuum generation in photonic crystal fibers with large hollow cores infiltrated with toluene. Optical Materials Express 8: 3568-3582

50. Yang X, Chang AS, Chen B, Gu C, Bond TC (2012) Multiplexed gas sensing based on Raman spectroscopy in photonic crystal fiber, in IEEE Photonics Conference 2012, 447-448

51. Yang X, Lu Y, Liu B, Yao J (2017) Fiber ring laser temperature sensor based on liquid-filled photonic crystal fiber. IEEE Sensors J 17:6948-6952

52. Ghenuche P, Rammler S, Joly NY, Scharrer M, Frosz M, Wenger J, Russell PSJ, Rigneault H (2012) Kagome hollow-core photonic crystal fiber probe for Raman spectroscopy. Opt Lett 37:4371-4373

53. Garcés-Chávez V, Dholakia K, Spalding G (2005) Extended-area optically induced organization of microparticles on a surface. Appl Phys Lett 86:031106

54. Iwasaka M, Asada H (2018) Floating photonic crystals utilizing magnetically aligned biogenic guanine platelets. Sci Rep 8:16940

55. Aly AH, Ryu S-W, Wu C-J (2008) Electromagnetic wave propagation characteristics in a one-dimensional metallic photonic crystal. J Nonlinear Opt Phys Mater 17:255-264

56. O’Sullivan F, Celanovic I, Jovanovic N, Kassakian J, Akiyama S, Wada K (2005) Optical characteristics of one-dimensional $\mathrm{Si} \mathrm{SiO}_{2}$ photonic crystals for thermophotovoltaic applications. J Appl Phys 97:033529

57. Ujihara K (1972) Reflectivity of metals at high temperatures. J Appl Phys 43:2376-2383

58. Celanovic I, Perreault D, Kassakian J (2005) Resonant-cavity enhanced thermal emission. Phys Rev B 72:075127

59. Gharaati A, Zare Z (2017) The effect of temperature on onedimensional nanometallic photonic crystals with coupled defects. Pramana 88:75

60. Banerjee A (2009) Enhanced temperature sensing by using onedimensional ternary photonic band gap structures. Prog Electromagn Res 11:129-137

61. Hopman WC, Pottier P, Yudistira D, Van Lith J, Lambeck PV, De La Rue RM et al (2005) Quasi-one-dimensional photonic crystal as a compact building-block for refractometric optical sensors. IEEE J Select Topics Quantum Electron 11:11-16

62. Wu L, Jia Y, Jiang L, Guo J, Dai X, Xiang Y et al (2016) Sensitivity improved SPR biosensor based on the $\mathrm{MoS}_{2}$ /graphene-aluminum hybrid structure. J Lightwave Technol 35:82-87

63. Kumar A, Kumar V, Suthar B, Bhargava A, Singh KS, OjhaS (2012) Wide range temperature sensors based on one-dimensional photonic crystal with a single defect, Int J Microwave Sci Technol, 2012

64. Li H (1980) Refractive index of silicon and germanium and its wavelength and temperature derivatives. J Phys Chem Ref Data 9:561-658

65. Salem M, Sailor M, Harraz F, Sakka T, Ogata Y (2006) Electrochemical stabilization of porous silicon multilayers for sensing various chemical compounds. J Appl Phys 100:083520

66. Alwan AM, Hayder AJ, Jabbar AA (2015) Study on morphological and structural properties of silver plating on laser etched silicon. Surf Coat Technol 283:22-28

67. Kaliteevski M, Iorsh I, Brand S, Abram R, Chamberlain J, Kavokin A et al (2007) Tamm plasmon-polaritons: possible electromagnetic 
states at the interface of a metal and a dielectric Bragg mirror. Phys Rev B 76:165415

68. Gaspar-Armenta JA, Villa F (2003) Photonic surface-wave excitation: photonic crystal-metal interface. JOSA B 20:2349-2354

69. Schroden RC, Al-Daous M, Blanford CF, Stein A (2002) Optical properties of inverse opal photonic crystals. Chem Mater 14:33053315

70. Aly AH, Ismaeel M, Abdel-Rahman E (2012) Comparative study of the one-dimensional dielectric and metallic photonic crystals. Opt Photon J 2:105-112

71. Meng Q-B, Fu C-H, Hayami S, Gu Z-Z, Sato O, Fujishima A (2001) Effects of external electric field upon the photonic band structure in synthetic opal infiltrated with liquid crystal. J Appl Phys 89:5794-5796

72. Ayyanar N, Raja GT, Sharma M, Kumar DS (2018) Photonic crystal fiber-based refractive index sensor for early detection of cancer. IEEE Sensors J 18:7093-7099
73. White IM, Fan X (2008) On the performance quantification of resonant refractive index sensors. Opt Express 16:1020-1028

74. El Beheiry M, Liu V, Fan S, Levi O (2010) Sensitivity enhancement in photonic crystal slab biosensors. Opt Express 18:2270222714

75. Sun M, Xu B, Dong X, Li Y (2012) Optical fiber strain and temperature sensor based on an in-line Mach-Zehnder interferometer using thin-core fiber. Opt Commun 285:3721-3725

76. Ghosh S, Rahman B (2019) Design of on-chip hybrid plasmonic Mach-Zehnder interferometer for temperature and concentration detection of chemical solution. Sensors Actuators B Chem 279: 490-502

Publisher's Note Springer Nature remains neutral with regard to jurisdictional claims in published maps and institutional affiliations. 